\title{
Long-Lasting Spinal Oxytocin Analgesia Is Ensured by the Stimulation of Allopregnanolone Synthesis Which Potentiates $\mathrm{GABA}_{\mathrm{A}}$ Receptor-Mediated Synaptic Inhibition
}

\author{
Pierre-Eric Juif, ${ }^{\star}$ Jean-Didier Breton, ${ }^{\star}$ Mathieu Rajalu, Alexandre Charlet, Yannick Goumon, and Pierrick Poisbeau \\ Centre National de la Recherche Scientifique and University of Strasbourg, Institut des Neurosciences Cellulaires et Intégratives, F-67084 Strasbourg, \\ France
}

Hypothalamospinal control of spinal pain processing by oxytocin $(\mathrm{OT})$ has received a lot of attention in recent years because of its potency to reduce pain symptoms in inflammatory and neuropathic conditions. However, cellular and molecular mechanisms underlying OT spinal antinociception are still poorly understood. In this study, we used biochemical, electrophysiological, and behavioral approaches to demonstrate that $\mathrm{OT}$ levels are elevated in the spinal cord of rats exhibiting pain symptoms, $24 \mathrm{~h}$ after the induction of inflammation with an intraplantar injection of $\lambda$-carrageenan. Using a selective OT receptor antagonist, we demonstrate that this elevated OT content is responsible for a tonic analgesia exerted on both mechanical and thermal modalities. This phenomenon appeared to be mediated by an OT receptor-mediated stimulation of neurosteroidogenesis, which leads to an increase in $\mathrm{GABA}_{\mathrm{A}}$ receptor-mediated synaptic inhibition in lamina II spinal cord neurons. We also provide evidence that this novel mechanism of OT-mediated spinal antinociception may be controlled by extracellular signal-related protein kinases, ERK1/2, after OT receptor activation. The oxytocinergic inhibitory control of spinal pain processing is emerging as an interesting target for future therapies since it recruits several molecular mechanisms, which are likely to exert a long-lasting analgesia through nongenomic and possibly genomic effects.

\section{Introduction}

Oxytocin (OT) is a nonapeptide synthetized by neurons located in the paraventricular (PVN) and supraoptic nuclei of the hypothalamus (Gimpl and Fahrenholz, 2001). If the neuroendocrine role of OT on the reproductive system is well known, its action as a neurotransmitter is yet to be understood. Oxytocinergic neurotransmission is ensured by parvocellular neurons of the PVN projecting to several regions of the CNS, including the spinal cord. In this particular region, there is a remarkable coexistence of OT-positive synaptic terminals (Saper et al., 1976; Swanson and McKellar, 1979; Sofroniew et al., 1981; Cechetto and Saper, 1988) and of OT binding sites in the most superficial layers of the dorsal horn and in autonomic nuclei (Reiter et al., 1994;

Received June 29, 2012; revised Sept. 11, 2013; accepted Sept. 11, 2013.

Author contributions: P.-E.J., J.-D.B., M.R., A.C., and P.P. designed research; P.-E.J., J.-D.B., M.R., A.C., Y.G., and P.P. performed research; P.-E.J., J.-D.B., M.R., A.C., Y.G., and P.P. analyzed data; P.-E.J., J.-D.B., M.R., A.C., and P.P. wrote the paper.

This work was supported by the following French institutions: Centre National de la Recherche Scientifique, Université de Strasbourg, Institut Universitaire de France (P.P.), Action Concertée Incitative jeunes chercheurs (P.P.), and Fondation pour la Recherche Médicale (P.P., J.-D.B.). J.-D.B. and M.R. received PhD scholarships from the French Ministère de la recherche et de I'Enseignement Supérieur. A.C. was supported by a PhD grant from Région Alsace and P.-E.J. was a postdoctoral fellow of Fond National de Recherche du Luxembourg. Publication costs were partly supported by the Neurex network (Program Interreg IV Upper Rhine), www.neurex.org. We thank Bernadette Lutz-Bucher for her excellent training and assistance while preparing the oxytocin dosage.

*P.-E.J. and J.-D.B. contributed equally to this work.

The authors declare no competing financial interests.

Correspondence should be addressed to Professor Pierrick Poisbeau, CNRS UPR 3212, Research Group Molecular Determinants of Pain, 21 rue René Descartes, F-67084 Strasbourg, France. E-mail: poisbeau@inci-cnrs.unistra.fr.

DOI:10.1523/JNEUROSCI.3084-12.2013

Copyright $\odot 2013$ the authors $\quad 0270-6474 / 13 / 3316617-10 \$ 15.00 / 0$
Véronneau-Longueville et al., 1999). In good agreement with these anatomical data, OT seems to exert a potent antinociceptive action during spinal pain processing. Local application of OT or its endogenous release following PVN stimulation strongly reduces action potential firing of second-order neurons after recruitment of nociceptive-specific $\mathrm{C}$ and A $\delta$ sensory neurons (Condés-Lara et al., 2003, 2006). OT-induced inhibition of nociceptive processing is further supported by the reduced glutamatergic transmission at sensorispinal synapses (Robinson et al., 2002), which contributes for a large part to short-lasting hyperexcitability (windup responses) and long-lasting plastic changes (long-term potentiation) in this preparation (Condés-Lara et al., 2006; DeLaTorre et al., 2009). Using patch-clamp recordings of lamina II neurons in spinal cord slices, we recently proposed OT action to be produced by a tonic synaptic release of GABA and by the inhibition of voltage-gated potassium currents responsible for repetitive firing in a subset of spinal neurons (Breton et al., 2008, 2009). These molecular mechanisms, and possibly others still unidentified, are likely to be recruited in inflammatory and neuropathic pain states since OT displayed significant analgesia in several rodent models (Lundeberg et al., 1993; Petersson et al., 2001; Yu et al., 2003; Condés-Lara et al., 2005; Miranda-Cardenas et al., 2006; Martínez-Lorenzana et al., 2008).

At this stage, results from our laboratory and other groups show that OT action on the excitability of superficial dorsal horn spinal neuron is potent, long-lasting, and particularly difficult to reverse (Breton et al., 2008, 2009; DeLaTorre et al., 2009). The major molecular target involved in OT-induced spinal antinociception is constituted by $\mathrm{GABA}_{\mathrm{A}}$ receptor channels $\left(\mathrm{GABA}_{\mathrm{A}} \mathrm{Rs}\right)$ 
but nothing is known on how OT can exert long-term antinociception and if OT can be tonically released by hypothalamospinal axons in pain conditions. To answer these questions, we used rats exhibiting inflammatory pain symptoms $24 \mathrm{~h}$ after an intraplantar injection of $\lambda$-carrageenan to measure the associated changes in spinal OT concentrations. Because these concentrations were elevated in hyperalgesic rats, we then characterized how these changes affect spinal nociceptive processing and the expression of pain symptoms. Eventually, a possible long-lasting action on $\mathrm{GABA}_{\mathrm{A}}$ receptor-mediated synaptic transmission was investigated.

\section{Materials and Methods}

Carrageenan model of pain

Male Sprague Dawley rats (9-11 weeks, 250-350 g; Janvier) were used for this part of the study. They were housed by group of four below standard conditions (room temperature, $22^{\circ} \mathrm{C} ; 12 \mathrm{~h} \mathrm{light/dark} \mathrm{cycle)}$ with ad libitum access to food and water. All animals were habituated to the room and handled by the experimenter for at least 2 weeks. After this period, a single intraplantar injection $(150 \mu \mathrm{l})$ of $\lambda$-carrageenan (3\% in $\mathrm{NaCl} 0.9 \%$; Sigma) was performed in the plantar surface of the right hindpaw for behavioral experiments whereas injections in both hindpaws were done for electrophysiological and biochemical studies. Control animals received an injection of $\mathrm{NaCl} 0.9 \%$ or no injection. All experiments were conducted in conformity with the directive of the European Committee Council Direction of September 22, 2010 (2010/63/ EU) and with a protocol agreement given by French Department of Agriculture (License No. 67-116 to PP). Carrageenan model of inflammatory sensitization and the associated intrathecal procedures were submitted and approved by the regional ethic committee for animal experimentation (CREMEAS authorization numbers AL 11/14/03/07 and AL 04/13/05/08).

\section{Oxytocin radioimmunoassay}

Tissue preparation. The 9- to 11-week-old male Sprague Dawley rats (Janvier) were deeply anesthetized with a mixture of ketamine $(75 \mathrm{mg} / \mathrm{kg}$, i.p.) and xylazine ( $5 \mathrm{mg} / \mathrm{kg}$, i.p.). They were killed $24 \mathrm{~h}$ after the bilateral injection of $\lambda$-carrageenan (carrageenan group: $n=5$ ) or saline injections (saline group: $n=5$ ). Five control rats (not injected) of the same weight were added to the study. The spinal cord of each rat was collected by hydraulic extrusion and cut in slices $1 \mathrm{~mm}$ thick by a tissue chopper (McIlwain). To limit degradation of the peptides, slice cutting and sample preparation was performed on melting ice. Spinal cord slices, placed in tubes containing $60 \mu \mathrm{l}$ of $\mathrm{HCl}(0.1 \mathrm{~N})$, were sonicated for $30 \mathrm{~s}$, and the resulting homogenate was centrifuged $15 \mathrm{~min}$ at $12,000 \mathrm{rpm}$. OT dosage was realized in $5 \mu \mathrm{l}$ aliquot fractions of the supernatant.

OT assay. The principle of the assay is based on the competition between endogenous unlabeled OT and exogenously supplied iodine-125 radiolabeled OT $\left({ }^{125} \mathrm{I}-\mathrm{OT}\right)$ for a specific antibody directed against OT (Moos et al., 1984). ${ }^{125} \mathrm{I}$-OT was produced in the laboratory by redox reaction between $\mathrm{OT}$ and ${ }^{125} \mathrm{I}-\mathrm{Na}$, catalyzed by lactoperoxidase and hydrogen peroxide (Moos et al., 1984). The product of this reaction was purified by HPLC. For each sample, incubations were performed with $100 \mu \mathrm{l}$ of spinal cord extract (unknown concentration of OT), $100 \mu \mathrm{l}$ of antiserum (diluted to give $50 \%$ of iodinated hormone bound with the antibody in the absence of antigen), and $100 \mu \mathrm{l}$ of ${ }^{125} \mathrm{I}-\mathrm{OT}$ (1000 counts/ min per tube). All dilutions were made in a barbital buffer $(0.05 \mathrm{M}$ sodium barbital, $\mathrm{pH} 8.6,2.5 \mathrm{mg} / \mathrm{l}$ bovine serum albumin, and $0.02 \%$ sodium merthiolate). After a $6 \mathrm{~d}$ incubation at $4^{\circ} \mathrm{C}$, bound and free hormone were separated by charcoal adsorption and then by adding 100 $\mu \mathrm{l}$ of bovine serum and $1 \mathrm{ml}$ of charcoal-dextran suspension (Charcoal Norit C 170, Fisher Scientific; Dextran T70, Pharmacia). Suspension was centrifuged at $800 \mathrm{rpm}$ for $20 \mathrm{~min}$ at $4^{\circ} \mathrm{C}$ and the supernatant containing the OT-antibody complexes was discarded; the ${ }^{125} \mathrm{I}$-OT retained by the charcoal suspension was quantified by a gamma counter (Packard) and compared with standard displacement curves obtained with known concentration of OT. OT content is expressed in $\mathrm{pg} / \mathrm{mm}$ of spinal cord and the vertebral level was identified before cutting.

\section{FosB/DFosB immunohistochemistry}

Immunohistochemistry was performed on a separate set of animals $(n=$ 6 per group). One day following intraplantar injection of either carrageenan or saline solution, rats were perfused intracardially with $150 \mathrm{ml}$ of PB (0.1 M, pH 7.4) followed by $500 \mathrm{ml}$ of a solution containing $4 \%$ paraformaldehyde in PB. After laminectomy, the lumbar spinal cord (L3-L5) segments were collected, immersed overnight in the same fixative, and washed the next day in phosphate saline buffer (PBS). Transverse sections of $40 \mu \mathrm{m}$ were prepared using a tissue slicer (Leica VT1000S). The sections were rinsed three times during $10 \mathrm{~min}$ in PBS and subsequently incubated for $1 \mathrm{~h}$ in a blocking solution composed of $5 \%$ donkey serum in PBS and $0.5 \%$ Triton X-100. The sections were then incubated overnight with a "pan-FosB" antibody (rabbit polyclonal 1:1000, ref. sc-48; Santa Cruz Biotechnology) raised against an internal region of FosB (i.e., recognizing both FosB and $\Delta$ FosB proteins) and with neurophysin-OT (1:250; kindly provided by Dr. Pierre Veinante, University of Strasbourg, Strasbourg, France) diluted in PBS containing 1\% normal serum and $0.5 \%$ Triton X-100. After washing with PBS $(5 \times 10$ $\mathrm{min})$, the sections were incubated $90 \mathrm{~min}$ with the secondary antibodies (Cy3:1:800, FITC: 1:80; Sigma-Aldrich) for $2 \mathrm{~h}$ at room temperature. After rinsing with PBS $(3 \times 10 \mathrm{~min})$, sections were mounted on gelatincoated slides. Three sections per animal were randomly chosen and the number of activated neurons (FosB) and of OT-positive cells (neurophysin-OT) in the paraventricular nucleus was assessed.

\section{Electrophysiological recordings}

Single-unit extracellular recording of dorsal horn spinal neurons in vivo. The 9- to 11-week-old Sprague Dawley rats were anesthetized with 3\% isoflurane in pure oxygen and a laminectomy was performed to expose the L4-L5 spinal cord segments. The animal was then placed on a stereotaxic frame, with the L4-L5 exposed region being firmly held by two clamps placed on the apophysis of the rostral and caudal intact vertebras. Isoflurane anesthesia was then reduced to $1.5 \%$ and a stainless steel electrode $(10 \mathrm{M} \Omega$; FHC) was lowered in the dorsal horn of the spinal cord after meninges removal. Single-unit extracellular recordings were all made from deep dorsal horn neurons, located 400-800 $\mu \mathrm{m}$ from the dorsal surface (see Fig. 1B), receiving convergent (non-noxious and noxious) sensory information from the ipsilateral hindpaw as previously described (Juif and Poisbeau, 2013). Voltage changes were amplified and filtered (low: $300 \mathrm{~Hz}$; high: $3000 \mathrm{~Hz}$ ) by a DAM-80 differential amplifier (WPI). Recordings were acquired at $10 \mathrm{kHz}$ and analyzed using the Spike 2 software, collecting data through a CED 1401 analog-to-digital interface (Cambridge Electronic Design). The stimulating threshold to evoke action potentials and their frequency of occurrence, resulting from the stimulation of the peripheral receptive field on the rat hindpaw, were attributed to the recruitment of A- and C-type sensory fibers based on their latency from the stimulus artifact as follows: $\mathrm{A} \beta:<20 \mathrm{~ms} ; \mathrm{A} \delta$ : $20-90 \mathrm{~ms}$; C: $90-300 \mathrm{~ms}$; post discharge: $300-800 \mathrm{~ms}$. Modulation of spinal cord neuron excitability was determined on action potential firing responses induced by electrical stimuli of the hindpaw ( $1 \mathrm{~ms}$ pulse duration, frequency $0.2 \mathrm{~Hz}$ ), at an intensity corresponding to 1.5 times the threshold for C-type sensory fiber activation.

Patch-clamp recording of lamina II neurons in spinal cord slices. Transverse slices of lumbar spinal cord were prepared from young adult Sprague Dawley rats (P21-P55; Janvier) deeply anesthetized with a mixture of ketamine $(75 \mathrm{mg} / \mathrm{kg}$, i.p.) and xylazine $(5 \mathrm{mg} / \mathrm{kg}$, i.p.), as described in previous studies (Keller et al., 2001). Although animals were younger than those used for the OT dosage, pain behavior, and in vivo electrophysiology, we found no difference in the synaptic current characteristics while recording from neurons in spinal cord slices of P21 rats and older animals (maximum age P55). This observation was in agreement with our previous observation (Keller et al., 2001) and data were pooled. Animals were killed $24 \mathrm{~h}$ after having performed the carrageenan or saline (bilateral) hindpaw injections. The lumbar spinal cord was collected by hydraulic extrusion and placed into ice-cold sucrose artificial CSF (S-ACSF) containing the following (in $\mathrm{mm}$ ): 248 sucrose, 11 glucose, $23 \mathrm{NaHCO}_{3}, 2 \mathrm{KCl}, 1.25 \mathrm{KH}_{2} \mathrm{PO}_{4}, 2 \mathrm{CaCl}_{2}$, and $1.3 \mathrm{MgSO}_{4}$ and was continuously saturated with $95 \% \mathrm{O}_{2}-5 \% \mathrm{CO}_{2}$. Transverse slices (300 $\mu \mathrm{m}$ thick) were cut from the lumbar segment of the spinal cord using a 
vibratome and stored at room temperature in an incubation chamber filled with regular ACSF containing the following (in mM): $126 \mathrm{NaCl}, 26$ $\mathrm{NaHCO}_{3}, 1.25 \mathrm{NaH}_{2} \mathrm{PO}_{4}, 2.5 \mathrm{KCl}, 2 \mathrm{CaCl}_{2}, 2 \mathrm{MgCl}_{2}$, and 10 glucose and continuously saturated with $95 \% \mathrm{O}_{2}-5 \% \mathrm{CO}_{2}$. Spinal cord slices were stored for at least $1 \mathrm{~h}$ at room temperature before being placed into the recording chamber. The slices were continuously superfused with oxygenated ACSF at a flow rate of $\sim 3 \mathrm{ml} / \mathrm{min}$.

All electrophysiological experiments were performed at room temperature in regular ACSF and lamina II neurons were recorded using the whole-cell configuration of the patch-clamp technique. The patch pipette was filled with a solution containing the following (in $\mathrm{mM}$ ): $125 \mathrm{CsCl}, 2 \mathrm{MgCl}_{2}, 2 \mathrm{Mg}$-ATP, $0.2 \mathrm{Na}$-GTP, and 10 HEPES, pH, 7.3 adjusted with $\mathrm{CsOH}$. Neurons were voltage clamped at $-60 \mathrm{mV}$ using an Axopatch 200B amplifier (Molecular Devices); series capacitance (Cs) and resistance were (Rs) compensated electronically throughout the experiments and only recordings lasting longer than 20 min with series resistance $<20 \mathrm{M} \Omega$ were considered for analysis. All recordings were low-pass filtered at $5 \mathrm{kHz}$, digitized at $10 \mathrm{kHz}$, and stored on computer using the Clampex module of pClamp software (Molecular Devices) before being analyzed. $\mathrm{GABA}_{\mathrm{A}}$ receptor-mediated miniature IPSCs $\left(\mathrm{GABA}_{\mathrm{A}} \mathrm{R}\right.$ mIPSCs) were pharmacologically isolated by using an ACSF containing $0.5 \mu \mathrm{m}$ tetrodotoxin (Latoxan), 2 mm kynurenic acid (Fluka), and $1 \mu \mathrm{M}$ strychnine (Sigma). Off-line, GABA $\mathrm{A}_{\mathrm{A}} \mathrm{mIPSC}$ were detected and analyzed individually using WinEDR and WinWCP software (courtesy of Dr. J. Dempster, University of Strathclyde, Glasgow, UK) to examine their frequency of occurrence, amplitude, and monoexponential decay time constants $(\tau)$.

\section{Allopregnanolone dosage}

Transverse slices of lumbar spinal cord were prepared from Sprague Dawley rats (between 30 and $50 \mathrm{~d}$ old; Janvier) anesthetized with a mixture of ketamine ( $75 \mathrm{mg} / \mathrm{kg}$, i.p.) and xylazine ( $5 \mathrm{mg} / \mathrm{kg}$, i.p.). Slices (1 $\mathrm{mm}$ length) were then placed for $3 \mathrm{~h}$ at room temperature in an incubation chamber filled with regular ACSF (see above) supplied with either $\left[\mathrm{Thr}^{4}, \mathrm{Gly}^{7}\right]$-oxytocin (TGOT; $\left.1 \mu \mathrm{M}\right)$ or TGOT $(1 \mu \mathrm{M})+\mathrm{d}\left(\mathrm{CH}_{2}\right)_{5^{-}}$ $\left[\mathrm{Tyr}(\mathrm{Me})^{2}, \mathrm{Thr}^{4}, \mathrm{Orn}^{8}{ }^{8}\right.$,des-Gly-NH${ }_{2}^{9}$-vasotocin (dOVT; $1 \mu \mathrm{M}$ ) continuously saturated with $95 \% \mathrm{O}_{2}-5 \% \mathrm{CO}_{2}$. After this incubation period, sections were homogenized in $200 \mu \mathrm{l}$ of ultrapure water and $600 \mu \mathrm{l}$ of methanol (100\%) were added. Samples were centrifuged during $30 \mathrm{~min}$ at $14,000 \times g\left(4^{\circ} \mathrm{C}\right)$. Then, supernatant was recovered and dried with a SpeedVac evaporator. Sample extracts were dissolved in $200 \mu$ l of ELISA sample buffer before quantification. An allopregnanolone-ELISA kit (GENTAUR) was used to quantify allopregnanolone concentrations in spinal cord extracts $(50 \mu \mathrm{l}$ in duplicate) following the manufacturer's instructions. For all tests, allopregnanolone standards were diluted in the sample buffer to avoid matrix effects. The coefficient of variation (CV) values were between 0 and $8 \%$. All samples with a higher $C V$ value were tested again to obtain a CV below or equal to $8 \%$. The calculated methodological detection limit of the batch of ELISA kit used for the study was $1 \mathrm{ng} / \mathrm{ml}$ of allopregnanolone. Amounts of allopregnanolone (ng) were normalized according to protein's concentrations (Protein Assay; Bio-Rad) determined before the extraction procedure. Note that cross reactivity of the antibody is $\sim 15 \%$ for progesterone and 17 hydroxyprogesterone (source: manufacturer) and $10.9 \%$ for allotetrahydrodeoxycorticosterone (present study).

\section{Behavioral testing}

Habituated adult Sprague Dawley rats ( $n=6$ per group) were used to measure nociceptive thresholds while applying mechanical and thermal heat stimuli on their hindpaws. All behavioral tests were done during the light period (between 9:00 and 16:00). Mechanical sensitivity was measured using a calibrated forceps (Bioseb) previously validated in our laboratory (Luis-Delgado et al., 2006). Briefly, the rat was loosely restrained with a towel masking the eyes to limit stress by environmental stimulation. The tips of the forceps were placed on each side of the hindpaw and a gradually increasing force was applied. The pressure producing paw withdrawal indicated the nociceptive threshold value. The thermal heat nociceptive response was assessed using Hargreaves' test (Bioseb), allowing the differentiation of the response of each hindpaw
(Hargreaves et al., 1988). Hindpaws are exposed to a radiant heat and the latency time required to induce paw withdrawal from the surface is taken as the nociceptive heat threshold. Nociceptive pressure threshold or withdrawal latency measurements were performed three times for each hindpaw and the values were averaged.

\section{Drugs and treatments}

We used the selective OT receptor agonist TGOT (Sigma) and antagonist dOVT (Bachem). OT receptors ligands were prepared as $\times 1000$ stock solutions in a molar acetic acid solution $0.25 \%(\mathrm{v} / \mathrm{v})$ in distilled water. These drugs were then added to the ACSF for in vitro electrophysiological experiments and to saline solution for behavioral experiments and in vivo electrophysiological recordings. The vehicle, used to prepare stock solutions and diluted at least 1000 times, had no electrophysiological or behavioral effects in the present study. To block neurosteroidogenesis in vitro, we incubated spinal cord slices $>3 \mathrm{~h}$ in oxygenated ACSF containing PK11195 [1-(2-chlorophenyl)- $N$-methyl- $N$-(1-methylpropyl)-3-isoquinoline carboxamide: an inhibitor of the cholesterol translocator protein complex (TSPO; Steraloids)] and finasteride [1, $(5 \alpha)$-androsten4-aza-3-one-17 $\beta$-( $N$-tert-butyl-carboxamide): an inhibitor of type II $5 \alpha$-reductase (Steraloids)]. In such experiments, the control condition consisted of adjacent slices incubated under the same conditions but in the absence of the pharmacological agents. In vivo, rats received a subcutaneous injection (scapular region), every $2 \mathrm{~d}$, of finasteride (FIN; 30 $\mathrm{mg} / \mathrm{kg}$ ) or Depo-Provera (4-pregnen-6 $\alpha$-methyl-17-ol-3, 20-dione acetate: inhibitor of $3 \alpha$-hydroxysteroid dehydrogenase; $5 \mathrm{mg} / \mathrm{kg}$; Steraloids) prepared in an olive oil vehicle with $20 \% \mathrm{v} / \mathrm{v}$ ethanol. Treatment was administered for at least 1 week before $\lambda$-carrageenan injection and until the end of the behavioral testing. To inhibit the activity of ERK1/2 in vitro, we incubated spinal cord slices in ACSF containing $20 \mu \mathrm{M}$ PD09859 (Merck-Millipore). With an $\mathrm{IC}_{50}$ of $2 \mu \mathrm{M}$, an inhibition of $\sim 90 \%$ of the ERK1/2 activity is likely to be achieved while using a steady-state concentration of $20 \mu \mathrm{M}$ (Alessi et al., 1995).

\section{Intrathecal injections}

Oxytocin receptor agonist (TGOT) and antagonist (dOVT) were administered intrathecally on rats, anesthetized with halothane 3\% (in pure oxygen). Acute intrathecal injection was realized by puncture through the intervertebral space between L5 and L6 using a $50 \mu$ l Hamilton microsyringe with a 26 gauge needle. A characteristic tail flick indicated penetration of the needle in the intrathecal space and ensures success for the delivery of the drug. After injection of the drug solution or of the vehicle $(\mathrm{NaCl} 9 \% ; 10 \mu \mathrm{l})$, the animal immediately recovered from halothane anesthesia and was placed in the testing chamber. To estimate possible spinal effect of the neurosteroids, rats were tested for mechanical thermal nociception 1,4 , and $24 \mathrm{~h}$ after the intrathecal injection, to check for recovery.

\section{Statistical analysis}

All data are expressed as mean \pm SEM. One-way or two-way ANOVA were used to analyze the effects of treatments (between factors), of side (between factors), and of time (within factor). Significant differences were assessed using Tukey's or Bonferroni post hoc tests (Statistica; StatSoft). Differences were considered to be statistically significant for $p<$ 0.05 . Kolmogorov-Smirnov test (KS test) was used to compare cumulative distributions and they were considered different when $p<0.01$. Two-tailed paired and unpaired Student's $t$ tests and nonparametric Mann-Whitney test were also used to compare two or more groups. Differences were considered to be statistically significant for $p<0.05$.

\section{Results}

\section{Increased spinal OT content exerts a tonic inhibitory control} of spinal nociceptive processing in carrageenan-injected animals

OT content from rat spinal cord was quantified by radioimmunoassay (RIA) $24 \mathrm{~h}$ after a bilateral intraplantar injection of $\lambda$-carrageenan and compared with the control groups: vehicleinjected (saline) and not injected (naive). In naive ( $n=5$ rats) and saline-injected rats $(n=5)$, OT content was similar for all 


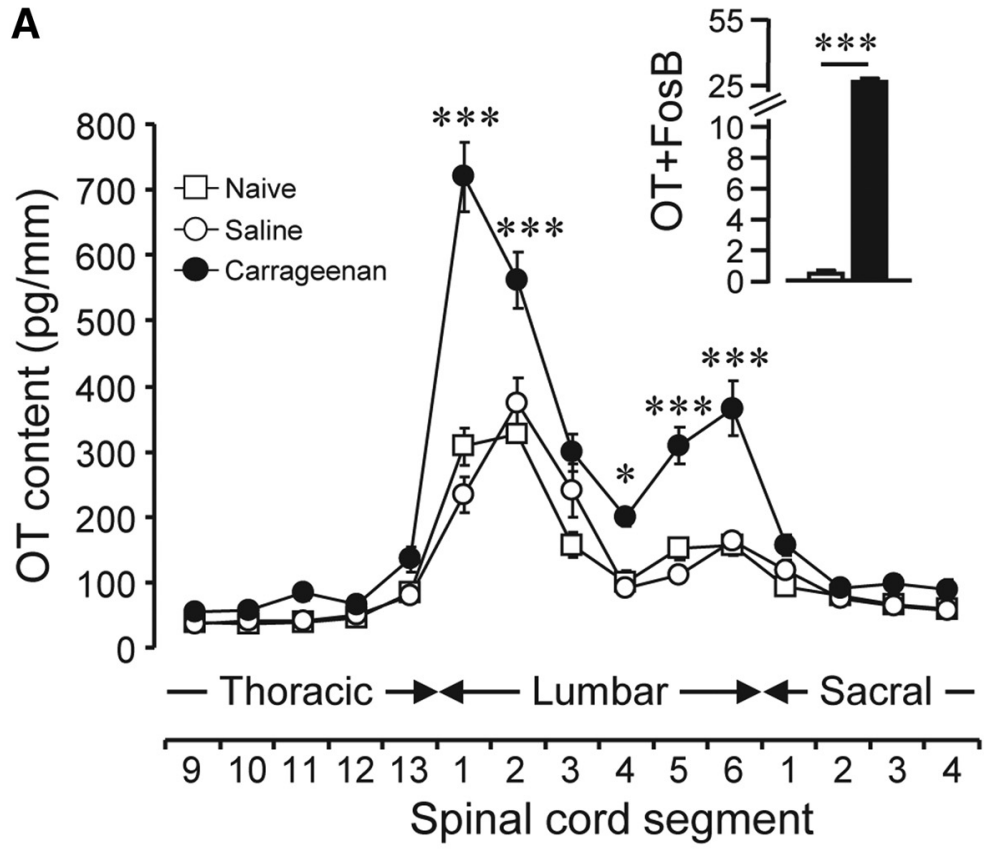

B Carrageenan-injected rat before dOVT
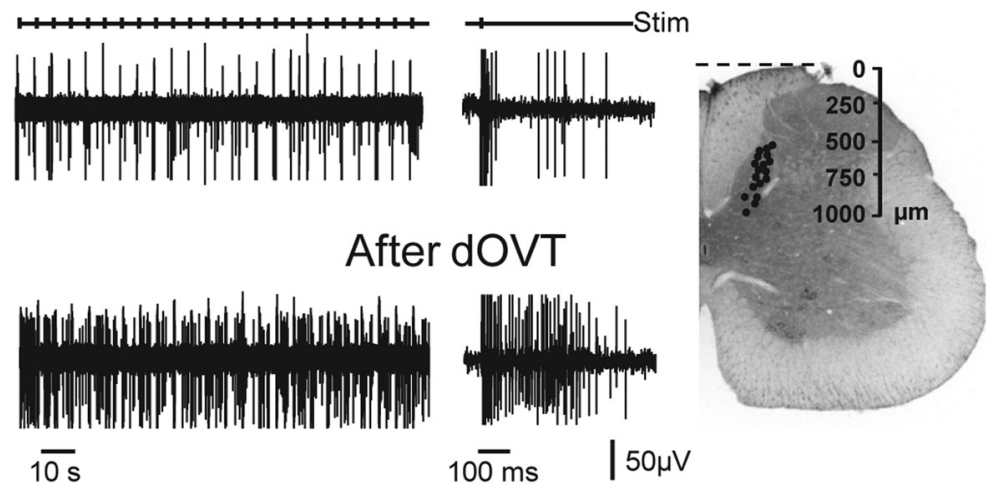

C

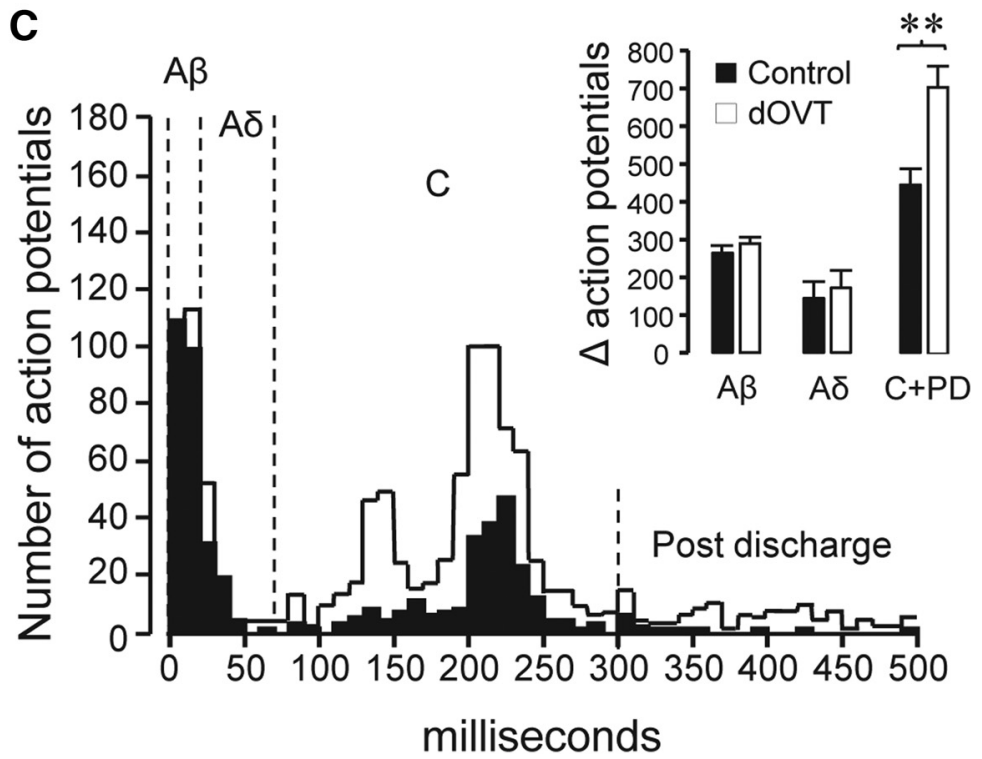

Figure 1. Elevated lumbar content in OT accounts for a limitation of spinal nociceptive processing in the carrageenan model of inflammatory pain sensitization. $A, 0 T$ content measured in thoracolumbar spinal vertebral segments (from T9 to S4) of naive (not injected, open squares), saline-injected (open circles), and carrageenan-injected (filled circles) animals. Twenty-four hours after spinal cord vertebral segments and was $<70 \mathrm{pg} / \mathrm{mm}$ of spinal cord. However, spinal OT content peaked at thoracic levels T2-T4 (Control: $103.3 \pm 5.8 \mathrm{pg} / \mathrm{mm}$; Saline: $98.8 \pm 7.7 \mathrm{pg} / \mathrm{mm}$; data not shown) and at lumbar levels L1-L2 and L5-L6 (Fig. 1A). In carrageenan-injected rats $(n=5)$, OT content was similar to the corresponding level of control and salineinjected groups but concentrations were significantly higher at most lumbar segments (L1-L2, L4-L6) with the Tukey post hoc test (Fig. 1A) after having performed an ANOVA between the different groups (two-way ANOVA, interaction between treatment and spinal cord segment: $\left.F_{(28,180)}=13.59, p<0.001\right)$.

Because oxytocinergic neurons, projecting to the spinal cord, are mostly located in the paraventricular nuclei, we next verified if the observed release of OT following carrageenan-induced inflammation resulted from the activation of these neurons. This was done by quantifying the number of activated oxytocinergic neurons using a double staining for neurophysin-OT and FosB $/ \Delta$ FosB after carrageenan or saline intraplantar injection (Fig. 1A, inset). As expected, the total number of FosB $/ \Delta$ FosB-immunoreactive cells in the PVN was significantly increased in carrageenan-treated animals $(41.7 \pm 2.0$, $n=4)$ compared with noninflamed animals (1.6 $\pm 0.5, n=4$; Mann-Whitney, $p<0.001)$. Interestingly, this was also true while counting neurophysin-OT-immunopositive neurons (control: $9.0 \pm 1.0$; carrageenan: $65.9 \pm 4.6$; Mann-Whitney, $p<$

\footnotetext{
$\leftarrow$

the injection, carrageenan animals had significantly higher $0 \mathrm{~T}$ content in L1, L2, L5, and L6 vertebral segments compared with naive and saline-injected animals. (Asterisks indicate statistical difference after Tukey's post hoc test within each spinal cord segment.) Inset, Histogram illustrating the number of OTneurophysin-positive neurons in the PVN also labeled for FosB/ $\Delta$ FosB in control (saline: white bar) and carrageenaninjected rats (black bar). $\boldsymbol{B}$, Representative in vivo recording from a carrageenan-injected rat (24 $\mathrm{h}$ after the injection) showing typical evoked action potential responses of a deep dorsal horn neuron located in the lumbar enlargement, after the stimulation of the corresponding ipsilateral hindpaw receptive field. Note that local application of the $0 \mathrm{~T}$ receptor antagonist dOVT $(1 \mu \mathrm{M})$ induced a strong increase in firing frequency (see expended traces in the middle). $0 n$ the right is indicated the location of recorded neurons. C, Histogram illustrating changes in the number of action potentials per period of $10 \mathrm{~min}$ (stimulation at $0.2 \mathrm{~Hz}$ ), before and after application of dOVT, for the neuron illustrated in $\boldsymbol{B}$. For all recorded neurons $(n=8)$, the mean number of action potentials per PAF type $[A \beta, A \delta, C$, and post discharge (PD)] is also illustrated in the inset. Statistical difference was assessed between groups using two-tailed paired Student's $t$ test. ${ }^{*} p<0.05$; ${ }^{* *} p<$ $0.01 ; * * * p<0.001$.
} 
Table 1. Action potential firing of WDR neurons recorded from the spinal cord of carrageenan-induced hyperalgesic rats

\begin{tabular}{llllll}
\hline Treatment & $A \beta$ & $A \delta$ & $C$ & $\begin{array}{l}\text { Post } \\
\text { discharge }\end{array}$ & $N$ \\
\hline Control & $264 \pm 20$ & $145 \pm 45$ & $486 \pm 106$ & $248 \pm 91$ & 8 \\
dOVT, intrathecal. & $289 \pm 17$ & $179 \pm 46$ & $693 \pm 108^{* *}$ & $361 \pm 95$ & 8 \\
\hline
\end{tabular}

Deep dorsal horn neuron action potential responses to electrical stimulation of the hindpaw (see Materials and Methods) are classified based on their latency to the stimulation as follows: $A \beta:<20 \mathrm{~ms} ; A \delta: 20-90 \mathrm{~ms} ; \mathrm{C}: 90-300$ $\mathrm{ms}$; post discharge: $300-800 \mathrm{~ms}$. Results were obtained from carrageenan-injected rats before (Control) and after local spinal dOVT application. Values are indicated as mean \pm SEM Statistical significance was assessed by comparing the groups before and after d0VT using two-tailed paired Student's $t$ test $\left({ }^{* *} p<0.01\right)$.

$0.001)$ fully in agreement with our RIA data. We observed that the number of colocalized OT/FosB neurons (Fig. $1 A$, inset) was significantly higher in carrageenan-injected rats $(26.7 \pm 1.5, n=4)$ compared with control animals $(0.4 \pm 0.2, n=4$; Mann-Whitney, $p<0.001)$. We next answered the question of what could be the functional consequences of the elevated OT spinal content on spinal nociceptive processing and $\mathrm{GABA}_{\mathrm{A}} \mathrm{R}$-mediated inhibitory synaptic transmission.

We first recorded dorsal horn neuron responses after the electrical stimulation of the hindpaw receptive field. We choose to record wide dynamic range neurons (WDR; Fig. $1 B$ ), which integrate convergent peripheral sensory information from nonnociceptive $\mathrm{A} \beta$ type and nociceptive $\mathrm{A} \delta$ and C-type primary afferent fibers (PAFs). Local spinal application of an OT receptor-antagonist, dOVT, was performed to reveal a possible effect of endogenous OT on inhibitory tone in saline- and carrageenan-injected rat. In saline-injected animals (and also in naive; data not shown), local lumbar dOVT application (1 $\mu \mathrm{M})$ had no obvious effect on deep dorsal horn neurons excitability in response to the activation of fast and slow conducting PAFs (number of action potentials as well as PAF thresholds were unchanged; data not shown, $n=6$ ). In contrast, C-type PAF threshold was significantly decreased in carrageenan-injected rats $(1.38 \pm 0.10 \mathrm{~mA}, n=8)$ compared with the control group (2.11 $\pm 0.71 \mathrm{~mA}, n=8$; unpaired Student's $t$ test: $t_{(14)}=1.02, p<$ $0.05)$, and this threshold was further decreased to $0.91 \pm 0.06 \mathrm{~mA}$ $(n=8)$ after topical application of dOVT on the spinal cord compared with value before dOVT (paired Student's $t$ test: $t_{(7)}=$ $5.95, p<0.001$ ). In addition, a train of 120 stimulations (frequency: $0.2 \mathrm{~Hz}$, intensity 1.5 times the C-type fiber threshold; pulse duration: $1 \mathrm{~ms}$ ) was used to quantify the number of action potentials emitted by the recorded neuron. As illustrated in Figure $1, B$ and $C$, a significant increase in the number of action potentials, resulting from the stimulation of C-type PAFs (post discharge included), was observed in carrageenan-injected rats after spinal application of dOVT (before dOVT: number of action potentials $=444 \pm 42$; after dOVT: number of action potentials $=703 \pm 56 ; n=8 ; t_{(7)}=6.621$ paired Student's $t$ test: $p<$ 0.01 ), whereas the response to A-type PAF activation was not affected during spinal application of dOVT (Fig. 1C; see also Table 1). In a subset of experiment we further demonstrated that $25 \%$ of the recorded WDR neurons $(n=20)$ were projecting neurons since they displayed a retrograde action potential after stimulation of the anterolateral spinal quadrant (intensity: 200 $\mu \mathrm{A}$, pulse duration: $100 \mu \mathrm{s}$ ), a few millimeters rostrally to the recording site. All together, these results show that peripheral inflammation induced by injection of carrageenan in the hindpaw increases OT content at the spinal lumbar level and this release of OT exerts a tonic inhibition of nociceptive C-type PAFs converging directly or indirectly on WDR neurons. Since all WDR neurons were submitted to this inhibitory action of OT (i.e., including projection neurons), we suggest here that supraspinal transmission of peripheral nociceptive messages will be reduced.

\section{Long-term activation of OT receptor potentiates fast GABAergic synaptic transmission}

To better understand how spinal OT could exert long-lasting antinociceptive effects in the neuronal networks of the spinal cord, we next incubated spinal cord slices from naive rats for at least $3 \mathrm{~h}$ at room temperature in regular ACSF or in ACSF containing $100 \mathrm{nM}$ TGOT, a selective OT receptor agonist. Then, $\mathrm{GABA}_{\mathrm{A}} \mathrm{R}$ mIPSCs were recorded from neurons in lamina II, which represent a major target for nociceptive C-type PAFs. Amplitude, frequency of occurrence, rise time, and decay time constant of $\mathrm{GABA}_{\mathrm{A}} \mathrm{R}$ mIPSCs were analyzed (see Materials and Methods). Compared with the control condition, $G_{A B A} R$ mIPSCs recorded after TGOT incubation differed only by their decaying kinetics (Fig. $2 A, D$, Table 2; one-way ANOVA: $F_{(4,34)}=$ $15.36, p<0.001)$. The mean monoexponential decay time constant $(\tau)$ was significantly slower compared with control (control: $20.4 \pm 1.5 \mathrm{~ms}, n=8$; TGOT: $32.5 \pm 2.3 \mathrm{~ms}, n=9$; Tukey post hoc test: $p<0.001)$. Interestingly, prolonged mIPSCs were never observed when spinal cord slices were incubated in the presence of TGOT (100 nM) and dOVT ( $1 \mu \mathrm{m}$; Table 2, Fig. $2 A, D$; Tukey post hoc test: $p>0.05)$. All together, these results strongly support the idea that endogenously released OT exerts a tonic inhibitory control on lamina II neurons mediated by a potentiation of $\mathrm{GABA}_{\mathrm{A}} \mathrm{R}$-mediated synaptic tone.

\section{OT long-lasting potentiation of $\mathrm{GABA}_{\mathrm{A}}$ mIPSCs is achieved by the stimulation of allopregnanolone synthesis: possible role of extracellular signal-regulated kinases}

Our laboratory has provided evidence indicating that endogenous neurosteroids are produced in the spinal cord after peripheral inflammation induced by intraplantar injection of carrageenan. In particular, the spinal synthesis of $3 \alpha 5 \alpha$-reduced neurosteroids limits the intensity of pain symptoms by potentiating GABAergic transmission in lamina II interneurons (Poisbeau et al., 2005). In good agreement with our previous findings and compared with control (saline injected), GABA $_{\mathrm{A}} \mathrm{R}$ mIPSCs recorded from lamina II spinal cord neurons of hyperalgesic rats (24 h after carrageenan intraplantar injection) exhibited a significant prolonged decaying phase (control: $\tau=20.4 \pm 1.2 \mathrm{~ms}, n=$ 9; carrageenan: $\tau=30.7 \pm 1.2 \mathrm{~ms}, n=12$; one-way ANOVA: $F_{(4,46)}=25.06, p<0.001$; Tukey post hoc test: $p<0.001$; Fig. $\left.2 D\right)$. No differences were noted for the other parameters, i.e., mean amplitude, rise time, and frequency of occurrence (data not shown). Interestingly, $\mathrm{GABA}_{\mathrm{A}} \mathrm{R}$ mIPSCs recorded from lamina II neurons during hyperalgesia were similar to those recorded from TGOT-incubated lamina II neurons of naive rats (Fig. 2D; TGOT incubation: $\tau=32.5 \pm 2.3 \mathrm{~ms}, n=9$; carrageenan injection: $\tau=$ $30.7 \pm 1.2 \mathrm{~ms}, n=12$ ). Furthermore, inhibition of $3 \alpha 5 \alpha-$ reduced neurosteroid synthesis by subcutaneous injection of finasteride (FIN: $5 \alpha$-reductase inhibitor; $30 \mathrm{mg} / \mathrm{kg}$ every $2 \mathrm{~d}$; Fig. $2 B-D)$, 1 week before the injection of carrageenan in the hindpaw, fully occluded the increase in $\mathrm{GABA}_{\mathrm{A}} \mathrm{R}$ mIPSC decays, which were similar to the control group (Tukey post hoc test: $p>$ 0.001; Fig. $2 B, D)$.

To reveal a possible oxytocinergic control of neurosteroidogenesis, we next incubated spinal cord slices of naive rats for $3 \mathrm{~h}$ in ACSF containing TGOT (100 nM) and two inhibitors of neurosteroidogenesis (Fig. $2 C$ ): the $5 \alpha$-reductase inhibitor finasteride $(50 \mu \mathrm{M})$ and the mitochondrial TSPO inhibitor PK11195 (10 
A

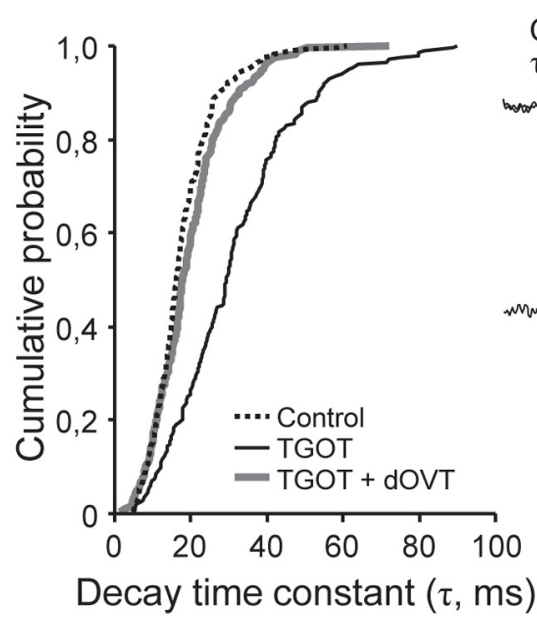

C

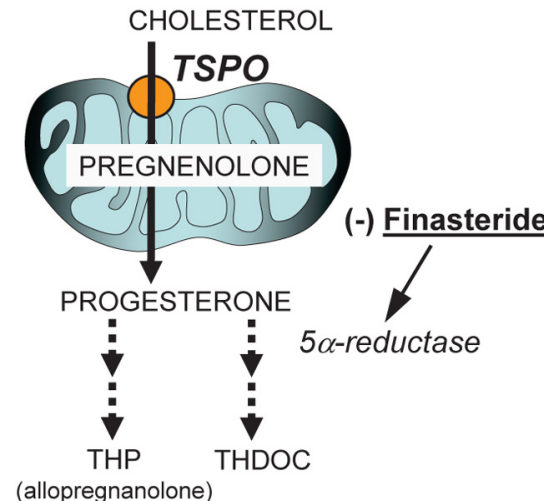

\section{Control} $\tau=18.9 \mathrm{~ms}$

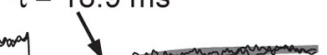

B

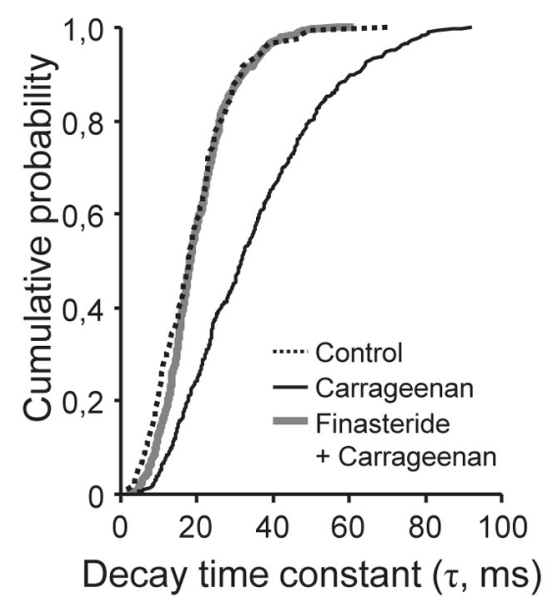

Decay time constant $(\tau, \mathrm{ms})$
TGOT + dOVT $\tau=17.9 \mathrm{~ms}$

$10 \mathrm{pA} \underset{20 \mathrm{~ms}}{\mathrm{~L}}$

D Decay time constant $(\tau, \mathrm{ms})$

$0 \quad 510152025303540$

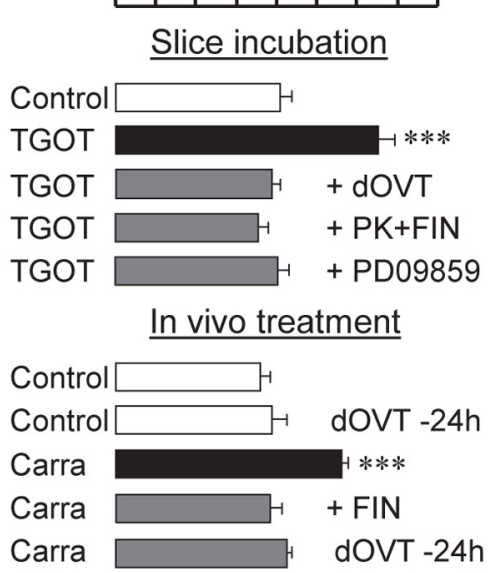

Control $\tau=19.2 \mathrm{~ms}$

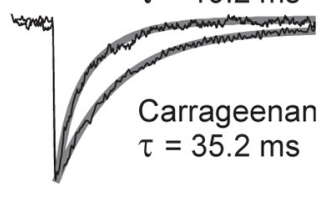

dOVT (-24h)

+ Carrageenan

$\tau=20.1 \mathrm{~ms}$

$10 \mathrm{pA} L$

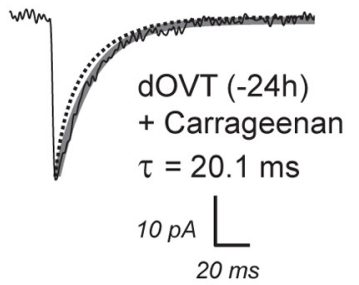

Figure 2. OT receptor activation increases the inhibitory charge carried by synaptic $\mathrm{GABA}_{\mathrm{A}} \mathrm{Rs}$ in lamina II neurons through the stimulation of $3 \alpha 5 \alpha$ neurosteroids synthesis. $A, B$, Cumulative probability graphs of GABA $\mathrm{mIPSC}$ decay time constants $(\tau)$ recorded in lamina II neurons of rat spinal cord slice $(\boldsymbol{A})$ incubated $3 \mathrm{~h}$ in control ACSF (Naive: dotted line, $n=281$ events), TG0T (100 nм: thin black line, $n=200$ events), or TGOT and dOVT (1 $\mu$ m; thick gray line, $n=207$ events) and (B) of control (not injected: dotted line, $n=117$ events) and carrageenan-injected animals, pretreated with finasteride (thick gray line, $n=616$ events) or not (thin black line, $n=414$ events). Traces in $A$ are an average of 10 individual GABA ${ }_{A} R$ mIPSCs in the different experimental conditions. Note that neurons incubated in TGOT exhibited significantly prolonged mIPSC decay time constant (compared with control, KS test, $p<0.001$ ) and this effect was occluded in slices, incubated in the presence of TGOT and dOVT (KS test, $p>0.05$ ). Decay time constant of GABA R mIPSCs recorded in the carrageenan condition were also slower compared with those of control animals (KS test, $p<0.001$ ) and of finasteride-pretreated carrageenan (KS test, $p<0.001$ ). C, Simplified schematic showing the metabolic pathway that leads to the production of $3 \alpha 5 \alpha$ neurosteroids: allopregnanolone (THP) and tetrahydrodeoxycorticosterone (THDOC), two potent positive allosteric modulators of GABA $A_{A}$ receptor function. Finasteride and PK11195 were used to inhibit $5 \alpha$-reductase activity and TSPO function, respectively. $\boldsymbol{D}$, Histogram comparing the mean decay time constants of $G A B A_{A} R$ mIPSCs recorded from lamina II neurons in various experimental conditions: (top graph) in vitro slice incubation ( $3 \mathrm{~h}$ ) with normal ACSF (control), TG0T alone (100 nM), or in combination with dOVT (1 $\mu \mathrm{M})$, PK11195 + Finasteride (PK + FIN), or PD09859 (20 $\mu \mathrm{M})$; (bottom graph) in vivo pretreatment of animals with finasteride $(30 \mathrm{mg} / \mathrm{kg}, \mathrm{S.c}$ ) for $7 \mathrm{~d}$ or dOVT (10 $\mathrm{ng}$, intrathecally) $24 \mathrm{~h}$ before carrageenan sensitization (Carra) are compared with a saline-injected group (control). Traces on the right are an average of 10 individual $G_{A B A_{A}} R$ mIPSCs recorded from control, carrageenan, and dOVT + carrageenan-treated rats. One-way ANOVAs performed to compare treatments for in vitro and in vivo conditions were significantly different. Tukey's post hoc test indicates significance at ${ }^{* * *} p<0.001$.

$\mu \mathrm{M})$. Inhibition of spinal neurosteroidogenesis in vitro occluded the effect of TGOT incubation on the decay of $\mathrm{GABA}_{\mathrm{A}} \mathrm{R}$ mIPSCs (Table 2, Fig. $2 B, D$; one-way ANOVA: $F_{(4,34)}=15.36, p<0.001$; Tukey post hoc test: $p>0.05$ ). This result strongly suggested that spinal OT receptor activation is required for the potentiation of $\mathrm{GABA}_{\mathrm{A}} \mathrm{R}$ mIPSCs by locally produced $3 \alpha 5 \alpha$-reduced neurosteroids. This conclusion was further supported by the quantification of allopregnanolone in lumbar spinal cord sections incubated for $3 \mathrm{~h}$ in TGOT alone or TGOT + dOVT. Allopregnanolone levels were $0.11 \pm 0.04 \mathrm{ng} / \mathrm{mg}$ protein $(n=10)$ after TGOT incubation but significantly lower and barely detectable after TGOT + dOVT $(0.02 \pm 0.03 \mathrm{ng} / \mathrm{mg}$ protein, $n=10$; MannWhitney, $p<0.01)$.
Although OT receptor-mediated intracellular signaling cascade is still unclear in the CNS, evidence suggests that ERKs are likely to constitute a converging pathway. We examined this hypothesis by analyzing the decaying kinetics of $\mathrm{GABA}_{\mathrm{A}} \mathrm{R}$ mIPSCs after a $3 \mathrm{~h}$ coincubation of spinal cord slices in the presence of TGOT (1 $\mu \mathrm{M})$ and of the MEK pathway inhibitor PD09859 (20 $\mu \mathrm{M})$. Under this experimental condition, the resulting mean decay time constant was of $20.6 \pm 0.9 \mathrm{~ms}(n=7)$ and similar to control slices (incubated in regular ACSF) taken from naive rats $(p>0.05$ Tukey post hoc test). This result likely indicated that ERK1/2 was indeed recruited after OT receptor activation and could account for the stimulation of neurosteroidogenesis and the subsequent tonic potentiation of $\mathrm{GABA}_{\mathrm{A}} \mathrm{R}$-mediated synap- 
Table 2. $0 \mathrm{~T}$ receptor activation potentiates $\mathrm{GABA}_{\mathrm{A}}$ receptor-mediated mIPSCs in lamina II neurons of the spinal cord

\begin{tabular}{llllr}
\hline mIPSC parameters & $\begin{array}{l}\text { Amplitude } \\
(\mathrm{pA})\end{array}$ & Decay $(\tau)$ & Frequency $(\mathrm{Hz})$ & $N$ \\
\hline Control incubation & $30.8 \pm 3.4$ & $20.4 \pm 1.5$ & $0.305 \pm 0.047$ & 8 \\
TGOT & $33.1 \pm 2.5$ & $32.5 \pm 2.3^{*}$ & $0.259 \pm 0.036$ & 9 \\
TG0T + dOVT & $33.0 \pm 1.2$ & $19.4 \pm 1.1$ & $0.322 \pm 0.046$ & 7 \\
dOVT incubation & $32.5 \pm 1.0$ & $21.3 \pm 0.5$ & $0.321 \pm 0.030$ & 10 \\
TGOT + PK11195 + finasteride & $35.6 \pm 1.2$ & $17.7 \pm 1.2$ & $0.444 \pm 0.076$ & 8 \\
\hline
\end{tabular}

Characteristics of $\mathrm{GABA}_{\mathrm{A}} \mathrm{R}$ mIPS(s recorded from lamina II neurons of rat spinal cord after a $3 \mathrm{~h}$ incubation in the following solutions: control (regular ACSF), TGOT (100 nM), TGOT (100 nM) + dOVT (1 $\mu \mathrm{M})$, dOVT (1 $\mu \mathrm{M})$, and TGOT $(100 \mathrm{~nm})+$ PK11195 $(10 \mu \mathrm{M})+$ finasteride $(50 \mu \mathrm{M})$. Values are indicated as mean \pm SEM Statistical significance between treatments was observed by one-way ANOVA only in the case of decay. Tukey's post hoc tests indicated a statistical difference for decay time constants of mIPSCs recorded from the TGOT-incubated spinal cord slices $\left({ }^{*} p<0.05\right)$.

tic transmission in lamina II spinal cord neurons. This preliminary result, while interesting, will need to be consolidated by additional investigations to fully dissect the underlying signaling cascade, which may involve other well known kinases.

To further strengthen this conclusion, dOVT was injected intrathecally in the lumbar segment of the rat spinal cord (10 ng; volume: $10 \mu \mathrm{l}$ ) $24 \mathrm{~h}$ before the intraplantar carrageenan injection. Spinal cord slices (of the lumbar enlargement) from these rats were then prepared, $48 \mathrm{~h}$ after dOVT intrathecal injection and $24 \mathrm{~h}$ after carrageenan intraplantar injection, to record $\mathrm{GABA}_{\mathrm{A}} \mathrm{R}$ mIPSCs from lamina II neurons. In good agreement with our in vitro incubation result, lamina II neurons recorded from dOVTpretreated and carrageenan-injected rats exhibited $G_{A B A} R$ mIPSCs similar to those recorded from the control group. In particular, we failed to reveal any differences in the mean decay time constant $(\tau=20.6 \pm 0.9 \mathrm{~ms} ; n=12 ; p>0.05$ Tukey post hoc test; Fig. 2D). Furthermore, intrathecal injection of dOVT (alone) in naive animals was not associated with any change in the decay time constant of $\mathrm{GABA}_{\mathrm{A}} \mathrm{R}$ mIPSCs (Fig. $2 D$; dOVT $-24 \mathrm{~h}: \tau=19.3 \pm 1.0 \mathrm{~ms}, n=9$; compared with control, $p>0.05$ Tukey post hoc test). All together, our results provide convincing evidence that a tonic activation of spinal OT receptors modulates $\mathrm{GABA}_{\mathrm{A}}$ inhibitory tone in carrageenan-induced pain animals in lamina II neurons. This mechanism is ensured by a stimulated synthesis of $3 \alpha 5 \alpha$-reduced neurosteroids, which is ERK1/2 dependent. We next attempted to demonstrate that this endogenous mechanism could be responsible for the reduction of pain symptoms in carrageenan-induced hyperalgesic animals.

\section{Tonic activation of spinal OT receptor stimulates the synthesis of $3 \alpha 5 \alpha$-reduced neurosteroids and limits mechanical and thermal heat hyperalgesia}

Figure 3 illustrates the time course of mechanical $(A 1)$ and thermal hot hyperalgesia (B1) measured after a unilateral intraplantar carrageenan injection (right paw, black symbols). While mechanical and thermal nociceptive thresholds of the noninjected paw remained similar to the baseline values, mechanical and thermal hyperalgesia develop rapidly for the carrageenan-injected paw and reached its maximum $7 \mathrm{~h}$ after the injection (mechanical pressure threshold decrease from $333.8 \pm 4.9 \mathrm{~g}$ before the injection to $19.5 \pm 2.2 \mathrm{~g}$; two-way ANOVA: time $\times$ treatment, $F_{(13,130)}=76.45, p<0.001$; Bonferroni: $p<0.001$; thermal latency threshold decrease from $11.9 \pm 0.5 \mathrm{~s}$ before the injection to $2.5 \pm 0.5 \mathrm{~s} ; n=6$ rats per group; two-way ANOVA: time $\times$ treatment, $F_{(9,81)}=10.04, p<0.001$; Bonferroni: $p<0.001$; Fig. $3 A 1-B 1)$. As indicated on the time course, and especially $24 \mathrm{~h}$ after carrageenan injection, rats remained hyperalgesic for mechanical $(\sim 43 \%)$ and thermal hot modalities ( $\sim 54 \%)$.
We next characterized the effects of intrathecal injections of saline, TGOT (100 nM), and dOVT (1 $\mu \mathrm{M})$ on mechanical and thermal nociceptive thresholds, $24 \mathrm{~h}$ after intraplantar carrageenan injection. This experiment was designed to demonstrate if endogenous OT tonus limits the intensity of pain symptom (dOVT intrathecal application) and if this OT-mediated antinociceptive control could be further potentiated (TGOT intrathecal application). Furthermore, TGOT and dOVT were administered to hyperalgesic rats, pretreated for at least 1 week with neurosteroidogenesis inhibitors (finasteride or Provera, see Materials and Methods) before the intraplantar carrageenan injection, to confirm or not that OT spinal analgesia requires the synthesis of $3 \alpha 5 \alpha$ neurosteroids. It has to be noticed that the finasteride or Provera treatment did not produce any significant changes in the nociceptive thresholds per se. In the control group of rats (intact neurosteroidogenesis), intrathecal injection of TGOT (100 nM) had no significant effect on mechanical and thermal nociceptive threshold/latency (Fig. 3A2-B2, left graphs). In contrast, intrathecal injection of dOVT $(1 \mu \mathrm{M})$ was associated with an immediate and significant decrease in mechanical threshold (from $205.6 \pm 23.3 \mathrm{~g}$ to $81.8 \pm 3.7 \mathrm{~g} ; n=6$; two-way ANOVA: time $\times$ treatment, $F_{(4,30)}=7.97, p<0.001$; Bonferroni: $p<0.001$; Fig. $3 A 2$, left graph) and thermal hot latency (from $5.8 \pm 0.4$ s to $3.2 \pm$ $0.5 \mathrm{~s} ; n=6$; two-way ANOVA: time $\times$ treatment, $F_{(4,30)}=8.13$, $p<0.001$; Bonferroni: $p<0.001$; Fig. 3B2, left graph), $4 \mathrm{~h}$ after intrathecal injection. As indicated in the Fig. 3, A2 and B2, exacerbation of mechanical and thermal hyperalgesia following dOVT intrathecal injection was never observed in finasteride- or Provera-pretreated rats. Our in vivo results strongly suggest that the tonic activation spinal OT receptors in hyperalgesic rats leads to the local production of $3 \alpha$-reduced neurosteroids, which limit the intensity of their pain symptoms. Potentiation of $\mathrm{GABA}_{\mathrm{A}}$ receptors in spinal nociceptive circuits are, for sure, a privileged target for this endogenous inhibitory control.

\section{Discussion}

Among the very few homeostatic analgesic mechanisms that have been identified so far in the CNS, cellular mechanisms leading to an efficient long-lasting antinociception are largely unknown. In this study, we have attempted to understand how the activation of descending hypothalamospinal oxytocinergic axons could exert such a tonic inhibitory control in the spinal cord, in a rat model of inflammatory sensitization following intraplantar carrageenan injection. Using different experimental approaches, biochemical, electrophysiological, and behavioral techniques, we show that the proinflammatory action of carrageenan in the paw is associated with the activation of oxytocinergic neurons in the PVN and leads to an elevation of OT spinal content, which may account for a tonic antihyperalgesic effect. In lamina II of the spinal cord, OT receptor activation seems to involve the recruitment of ERK1/2 and the stimulation of the local synthesis of allopregnanolone, which in turn increase $\mathrm{GABA}_{\mathrm{A}}$ receptormediated inhibitory tone.

Acute OT control of spinal nociceptive processes and pain responses is well documented and several mechanisms have been identified to explain these effects. In previous studies, endogenous OT release in the spinal cord was triggered by an electrical stimulation of PVN neurons (Martínez-Lorenzana et al., 2008) and produced a massive and sustained reduction in action potential firing in dorsal horn neurons (Yirmiya et al., 1990; Shiraishi et al., 1995; Condés-Lara et al., 2006). This reduction is fully prevented by selective OT receptor antagonist and affects selectively nociceptive inputs carried by $\mathrm{A} \delta$ and $\mathrm{C}$ fibers (Condés-Lara et al., 
$\mathrm{A}_{1}$

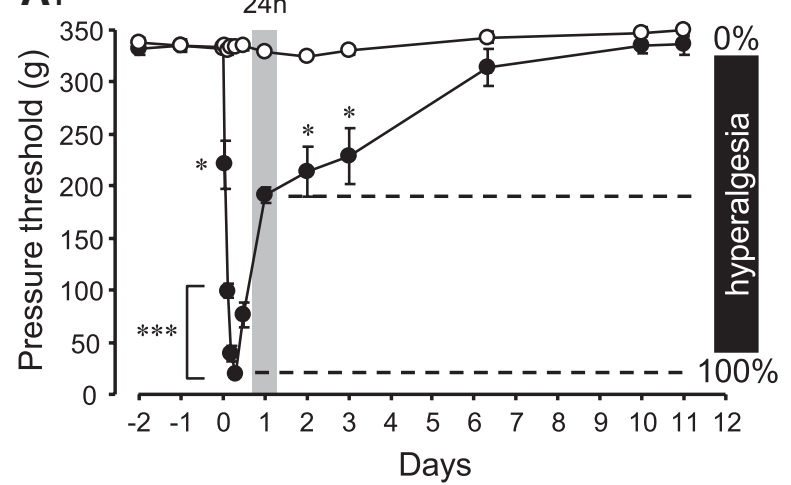

B1

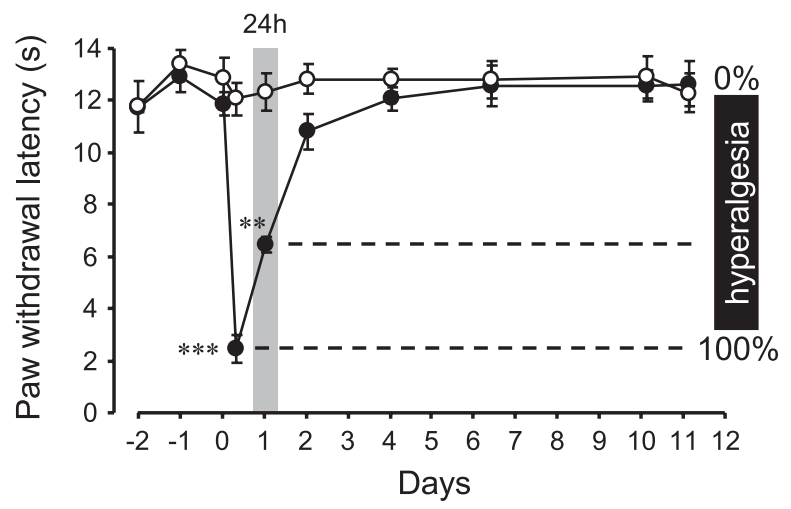

A2

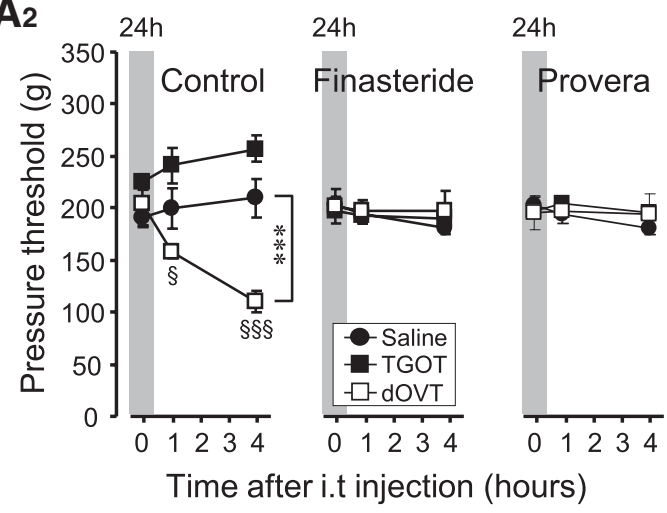

B2

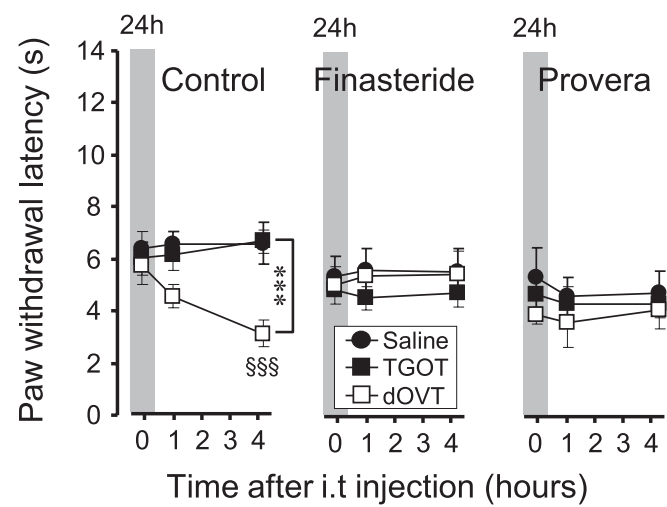

Figure 3. Limitation of mechanical and thermal hyperalgesia in carrageenan-injected rats resulting from the stimulation $3 \alpha 5 \alpha$ neurosteroid synthesis by endogenous oxytocin. $\mathbf{A 1}$, $\boldsymbol{B}$, Time course of mechanical (pressure, $\boldsymbol{A}$ ) and thermal (heat, $\boldsymbol{B}$ 1) nociceptive thresholds measured from the right (carrageenan-injected, black circle) hindpaw and the left (noninjected, open circles) hindpaw. The gray bar indicates values obtained $24 \mathrm{~h}$ after the carrageenan injection, which will be used as controls for the subsequent intrathecal injections (A2 and B2). Two-way ANOVA (repeated measures; time $X$ side) revealed a significant interaction for pressure and latency thresholds. Statistical differences are indicated after Bonferroni post hoc tests while comparing the thresholds between side for a given time point $\left({ }^{*} p<0.05 ;{ }^{* *} p<0.01 ;{ }^{* * *} p<0.001\right) . A 2, B 2$, Mechanical and thermal nociceptive thresholds changes in carrageenan-injected hyperalgesic rats (24 h, gray bar), assessed before $(0 \mathrm{~h})$ and after ( 1 and $4 \mathrm{~h}$ ) intrathecal injection of saline, TGOT (100 nM), or dOVT (1 $\mu \mathrm{M})$. Three groups of rats were used and pretreated 1 week before carrageenan injection with subcutaneous vehicle (control, left graphs), finasteride (30 mg/kg, middle graphs), or Depo-Provera (20 mg/kg, right graphs). Note that dOVT-induced hyperalgesia (seen in control condition) was never observed in finasteride or Provera-pretreated animals. Two-way ANOVA (repeated measures, time $\times$ treatment) revealed a significant interaction only in the control condition for pressure and latency thresholds. Statistical differences are indicated after Bonferroni post hoc tests while comparing the thresholds between groups for a given time point $\left({ }^{* * *} p<0.001\right.$ compared with saline) and within time for each group $\left({ }^{\S} p<0.05 ;{ }^{\S \S} p<0.001\right.$ compared with time 0$)$.

2006; Miranda-Cardenas et al., 2006). Many lines of evidence indicate that acute spinal OT analgesia is associated with a reinforcement of GABA receptor-mediated inhibition. In a recent study, we proposed that oxytocinergic control is relayed by a subset of glutamatergic neurons in lamina II, which recruit most, if not all, GABAergic interneurons (Breton et al., 2008). This hypothesis is supported by the elevated frequency of spontaneously occurring $\mathrm{GABA}_{\mathrm{A}}$ IPSCs, but not of miniature events. Whether this increase in $\mathrm{GABA}_{\mathrm{A}}$ receptor-mediated synaptic transmission is responsible for the inhibition of glutamatergic sensorispinal synapses (presynaptic inhibition) and/or of secondorder spinal neuron integration is still unclear (Robinson et al., 2002). In all cases, OT action results in a strong reduction of spinal pain processing and this might also involve changes in the integration properties of dorsal horn interneurons, as previously suggested (Breton et al., 2009).

Here, we demonstrate that OT receptors are not only tonically activated in inflammatory pain states but also inhibit spinal nociceptive processing (Fig. 1B) and exert significant antihyperalgesia in carrageenan-induced pain model (Fig. 3). As shown by the high number of OT neurons immunoreactive for FosB/ $\Delta$ FosB, the elevated OT content in lumbar vertebral segments of the spinal cord is likely to result from a sustained activation of hypothalamospinal oxytocinergic axons. It is interesting to note that the levels of OT in the blood, the CSF, and sometimes CNS tissue (spinal cord and encephalon), are directly related to the intensity of pain symptoms. Indeed, children exhibiting recurrent abdominal pain show reduced blood OT concentration (Alfvén et al., 1994), as well as in adult patients with low back pain (Yang, 1994). Recently, OT content was measured in the blood, CSF, and lumbar spinal tissues collected from neuropathic rats (Martínez-Lorenzana et al., 2008). OT concentration in the blood and CSF of neuropathic rats was significantly lower compared with control rats, whereas no change was observed in lumbar spinal tissues. In the carrageenan model of inflammatory pain, we found that spinal OT contents are indeed elevated and this difference is likely to be related to the inflammatory nature of the painful stimulus and/or the moment where tissues were collected and analyzed after pain induction. In good agreement, OT content in the CSF is increased $24 \mathrm{~h}$ after a sciatic nerve loose ligation and returned to control (pain free) values, $8 \mathrm{~d}$ later (Martínez-Lorenzana et al., 2008). Unfortunately, there is no similar time course for spinal OT available in the literature.

There is very little (and sometimes contradictory) information regarding the intracellular molecular mechanisms recruited by central OT receptor activation. Several reports are pointing 
out the possible major contribution of mitogen-activated protein kinases (MAPKs) in the control of pathological pain processes (Ji et al., 2009). In line with this idea, anxiolysis produced by hypothalamic infusion of OT was recently demonstrated to result from the activation of ERK, a preeminent member of the MAPK family (Blume et al., 2008). ERK activation in pain conditions might promote long-lasting genomic changes but was also demonstrated to change spinal neuron excitability (Hu and Gereau, 2003; Hu et al., 2003). In this study, we provide preliminary evidence for a novel ERK-driven mechanism of analgesia, which involves the stimulation of neurosteroidogenesis, more specifically the synthesis of the well known analgesic neurosteroid allopregnanolone (Charlet et al., 2008). Interestingly, only the most superficial layers and particularly the neurons in lamina II are capable of producing allopregnanolone from cholesterol (Inquimbert et al., 2008). Since the neurosteroid-mediated longlasting OT analgesia affects only C-type nociceptive messages, we can hypothesize that the increase of inhibitory tone is located in this lamina highly innervated by $\mathrm{C}$ nociceptors. As observed in Figure 3, we failed to observe any additional analgesic effect following TGOT administration. This leads us to suggest that $24 \mathrm{~h}$ following induction of inflammation the neurosteroid synthesis has reached its maximum. In a previously published paper (Poisbeau et al., 2005), acute inhibition of neurosteroidogenesis by finasteride (single injection $24 \mathrm{~h}$ before carrageenan injection) was associated with a significant decrease of thermal hot but not of mechanical nociceptive threshold. In this study, finasteride treatment was without effect. Without knowing the underlying mechanisms, we can only speculate that this might be due to homeostatic compensation resulting from the repeated exposure to finasteride (three injections every $2 \mathrm{~d}$ ). How ERK activation can stimulate neurosteroidogenesis in the CNS is still unknown. The only available data refer to a possible steroidogenic role of ERK in peripheral gonadic cells (Cameron et al., 1996; Das et al., 1996; Gyles et al., 2001; Martinelle et al., 2004). Recently, a functional interaction between ERK and the TSPO complex was suggested (Poderoso et al., 2008, 2009). The contribution of ERK could possibly be mediated by its binding to the steroidogenic associated receptor protein, a major component of TSPO complexes (cholesterol translocator protein complexes). This working hypothesis remains to be demonstrated in the spinal cord and will require further investigations.

In summary, this study provides evidence indicating that increased release of OT by hypothalamospinal axons in hyperalgesic rats, tonically activates lamina II dorsal horn spinal OT receptors and, at least, the downstream intracellular effector ERK1/2. This mechanism leads to the stimulation of the synthesis of analgesic neurosteroids. We demonstrate this novel mechanism to be responsible for a sustained analgesic control in this particular inflammatory pain model. Analgesia is apparently achieved, at least, by an increase in the quantal inhibitory charge carried by synaptic $\mathrm{GABA}_{\mathrm{A}}$ receptors in lamina II neurons, via an allosteric potentiation by allopregnanolone-like neurosteroids.

\section{References}

Alessi DR, Cuenda A, Cohen P, Dudley DT, Saltiel AR (1995) PD 098059 is a specific inhibitor of the activation of mitogen-activated protein kinase kinase in vitro and in vivo. J Biol Chem 270:27489-27494. CrossRef Medline

Alfvén G, de la Torre B, Uvnäs-Moberg K (1994) Depressed concentrations of oxytocin and cortisol in children with recurrent abdominal pain of non-organic origin. Acta Paediatr 83:1076-1080. CrossRef Medline

Blume A, Bosch OJ, Miklos S, Torner L, Wales L, Waldherr M, Neumann ID (2008) Oxytocin reduces anxiety via ERK1/2 activation: local effect within the rat hypothalamic paraventricular nucleus. Eur J Neurosci 27: 1947-1956. CrossRef Medline

Breton JD, Veinante P, Uhl-Bronner S, Vergnano AM, Freund-Mercier MJ, Schlichter R, Poisbeau P (2008) Oxytocin-induced antinociception in the spinal cord is mediated by a subpopulation of glutamatergic neurons in lamina I-II which amplify GABAergic inhibition. Mol Pain 4:19. CrossRef Medline

Breton JD, Poisbeau P, Darbon P (2009) Antinociceptive action of oxytocin involves inhibition of potassium channel currents in lamina II neurons of the rat spinal cord. Mol Pain 5:63. CrossRef Medline

Cameron MR, Foster JS, Bukovsky A, Wimalasena J (1996) Activation of mitogen-activated protein kinases by gonadotropins and cyclic adenosine 5'-monophosphates in porcine granulosa cells. Biol Reprod 55:111-119. CrossRef Medline

Cechetto DF, Saper CB (1988) Neurochemical organization of the hypothalamic projection to the spinal cord in the rat. J Comp Neurol 272:579604. CrossRef Medline

Charlet A, Lasbennes F, Darbon P, Poisbeau P (2008) Fast non-genomic effects of progesterone-derived neurosteroids on nociceptive thresholds and pain symptoms. Pain 139:603-609. CrossRef Medline

Condés-Lara M, González NM, Martínez-Lorenzana G, Delgado OL, FreundMercier MJ (2003) Actions of oxytocin and interactions with glutamate on spontaneous and evoked dorsal spinal cord neuronal activities. Brain Res 976:75-81. CrossRef Medline

Condés-Lara M, Maie IA, Dickenson AH (2005) Oxytocin actions on afferent evoked spinal cord neuronal activities in neuropathic but not in normal rats. Brain Res 1045:124-133. CrossRef Medline

Condés-Lara M, Rojas-Piloni G, Martínez-Lorenzana G, Rodríguez-Jiménez J, López Hidalgo M, Freund-Mercier MJ (2006) Paraventricular hypothalamic influences on spinal nociceptive processing. Brain Res 1081: 126-137. CrossRef Medline

Das S, Maizels ET, DeManno D, St Clair E, Adam SA, Hunzicker-Dunn M (1996) A stimulatory role of cyclic adenosine $3^{\prime}, 5^{\prime}$-monophosphate in follicle-stimulating hormone-activated mitogen-activated protein kinase signaling pathway in rat ovarian granulosa cells. Endocrinology 137:967974. CrossRef Medline

DeLaTorre S, Rojas-Piloni G, Martínez-Lorenzana G, Rodríguez-Jiménez J, Villanueva L, Condés-Lara M (2009) Paraventricular oxytocinergic hypothalamic prevention or interruption of long-term potentiation in dorsal horn nociceptive neurons: electrophysiological and behavioral evidence. Pain 144:320 -328. CrossRef Medline

Gimpl G, Fahrenholz F (2001) The oxytocin receptor system: structure, function, and regulation. Physiol Rev 81:629-683. Medline

Gyles SL, Burns CJ, Whitehouse BJ, Sugden D, Marsh PJ, Persaud SJ, Jones PM (2001) ERKs regulate cyclic AMP-induced steroid synthesis through transcription of the steroidogenic acute regulatory (StAR) gene. J Biol Chem 276:3488834895. CrossRef Medline

Hargreaves K, Dubner R, Brown F, Flores C, Joris J (1988) A new and sensitive method for measuring thermal nociception in cutaneous hyperalgesia. Pain 32:77-88. CrossRef Medline

Hu HJ, Gereau RW 4th (2003) ERK integrates PKA and PKC signaling in superficial dorsal horn neurons. II. Modulation of neuronal excitability. J Neurophysiol 90:1680-1688. CrossRef Medline

Hu HJ, Glauner KS, Gereau RW 4th (2003) ERK integrates PKA and PKC signaling in superficial dorsal horn neurons. I. Modulation of A-type K+ currents. J Neurophysiol 90:1671-1679. CrossRef Medline

Inquimbert P, Rodeau JL, Schlichter R (2008) Regional differences in the decay kinetics of GABA(A) receptor-mediated miniature IPSCs in the dorsal horn of the rat spinal cord are determined by mitochondrial transport of cholesterol. J Neurosci 28:3427-3437. CrossRef Medline

Ji RR, Gereau RW 4th, Malcangio M, Strichartz GR (2009) MAP kinase and pain. Brain Res Rev 60:135-148. CrossRef Medline

Juif PE, Poisbeau P (2013) Neurohormonal effects of oxytocin and vasopressin receptor agonists on spinal pain processing in male rats. Pain 154:1449-1456. CrossRef Medline

Keller AF, Coull JA, Chery N, Poisbeau P, De Koninck Y (2001) Regionspecific developmental specialization of GABA-glycine cosynapses in laminas I-II of the rat spinal dorsal horn. J Neurosci 21:7871-7880. Medline

Luis-Delgado OE, Barrot M, Rodeau JL, Schott G, Benbouzid M, Poisbeau P, Freund-Mercier MJ, Lasbennes F (2006) Calibrated forceps: a sensitive 
and reliable tool for pain and analgesia studies. J Pain 7:32-39. CrossRef Medline

Lundeberg T, Meister B, Björkstrand E, Uvnäs-Moberg K (1993) Oxytocin modulates the effects of galanin in carrageenan-induced hyperalgesia in rats. Brain Res 608:181-185. CrossRef Medline

Martinelle N, Holst M, Söder O, Svechnikov K (2004) Extracellular signalregulated kinases are involved in the acute activation of steroidogenesis in immature rat Leydig cells by human chorionic gonadotropin. Endocrinology 145:4629-4634. CrossRef Medline

Martínez-Lorenzana G, Espinosa-López L, Carranza M, Aramburo C, PazTres C, Rojas-Piloni G, Condés-Lara M (2008) PVN electrical stimulation prolongs withdrawal latencies and releases oxytocin in CSF, plasma, and spinal cord tissue in intact and neuropathic rats. Pain 140:265-273. CrossRef Medline

Miranda-Cardenas Y, Rojas-Piloni G, Martínez-Lorenzana G, RodríguezJiménez J, López-Hidalgo M, Freund-Mercier MJ, Condés-Lara M (2006) Oxytocin and electrical stimulation of the paraventricular hypothalamic nucleus produce antinociceptive effects that are reversed by an oxytocin antagonist. Pain 122:182-189. CrossRef Medline

Moos F, Freund-Mercier MJ, Guerné Y, Guerné JM, Stoeckel ME, Richard P (1984) Release of oxytocin and vasopressin by magnocellular nuclei in vitro: specific facilitatory effect of oxytocin on its own release. J Endocrinol 102:63-72. CrossRef Medline

Petersson M, Wiberg U, Lundeberg T, Uvnäs-Moberg K (2001) Oxytocin decreases carrageenan induced inflammation in rats. Peptides 22:14791484. CrossRef Medline

Poderoso C, Converso DP, Maloberti P, Duarte A, Neuman I, Galli S, Cornejo Maciel F, Paz C, Carreras MC, Poderoso JJ, Podestá EJ (2008) A mitochondrial kinase complex is essential to mediate an ERK1/2-dependent phosphorylation of a key regulatory protein in steroid biosynthesis. PLoS One 3:e1443. CrossRef Medline

Poderoso C, Maloberti P, Duarte A, Neuman I, Paz C, Cornejo Maciel F, Podesta EJ (2009) Hormonal activation of a kinase cascade localized at the mitochondria is required for StAR protein activity. Mol Cell Endocrinol 300:37-42. CrossRef Medline

Poisbeau P, Patte-Mensah C, Keller AF, Barrot M, Breton JD, Luis-Delgado
OE, Freund-Mercier MJ, Mensah-Nyagan AG, Schlichter R (2005) Inflammatory pain upregulates spinal inhibition via endogenous neurosteroid production. J Neurosci 25:11768-11776. CrossRef Medline

Reiter MK, Kremarik P, Freund-Mercier MJ, Stoeckel ME, Desaulles E, Feltz P (1994) Localization of oxytocin binding sites in the thoracic and upper lumbar spinal cord of the adult and postnatal rat: a histoautoradiographic study. Eur J Neurosci 6:98-104. CrossRef Medline

Robinson DA, Wei F, Wang GD, Li P, Kim SJ, Vogt SK, Muglia LJ, Zhuo M (2002) Oxytocin mediates stress-induced analgesia in adult mice. J Physiol 540:593-606. CrossRef Medline

Saper CB, Loewy AD, Swanson LW, Cowan WM (1976) Direct hypothalamoautonomic connections. Brain Res 117:305-312. CrossRef Medline

Shiraishi T, Onoe M, Kojima T, Sameshima Y, Kageyama T (1995) Effects of hypothalamic paraventricular nucleus: electrical stimulation produce marked analgesia in rats. Neurobiology 3:393-403. Medline

Sofroniew MV, Weindl A, Schrell U, Wetzstein R (1981) Immunohistochemistry of vasopressin, oxytocin and neurophysin in the hypothalamus and extrahypothalamic regions of the human and primate brain. Acta Histochem [Suppl 24]:79-95. Medline

Swanson LW, McKellar S (1979) The distribution of oxytocin- and neurophysin-stained fibers in the spinal cord of the rat and monkey. J Comp Neurol 188:87-106. CrossRef Medline

Véronneau-Longueville F, Rampin O, Freund-Mercier MJ, Tang Y, Calas A, Marson L, McKenna KE, Stoeckel ME, Benoit G, Giuliano F (1999) Oxytocinergic innervation of autonomic nuclei controlling penile erection in the rat. Neuroscience 93:1437-1447. CrossRef Medline

Yang J (1994) Intrathecal administration of oxytocin induces analgesia in low back pain involving the endogenous opiate peptide system. Spine 19:867-871. CrossRef Medline

Yirmiya R, Ben-Eliyahu S, Shavit Y, Marek P, Liebeskind JC (1990) Stimulation of the hypothalamic paraventricular nucleus produces analgesia not mediated by vasopressin or endogenous opioids. Brain Res 537:169174. CrossRef Medline

Yu SQ, Lundeberg T, Yu LC (2003) Involvement of oxytocin in spinal antinociception in rats with inflammation. Brain Res 983:13-22. CrossRef Medline 